\title{
The Prognostic Value of Preoperative Serum Lactate Dehydrogenase (LDH) Levels in Patients Underwent Curative-intent Hepatectomy For Colorectal Liver Metastases: A Two-Center Cohort Study
}

\section{Long Bai}

Sun Yat-sen University Cancer Center

Ze-Yu Lin

Sixth Affiliated Hospital of Sun Yat-sen University

Yun-Xin Lu

Sun Yat-sen University Cancer Center

Qin Chen

Sixth Affiliated Hospital of Sun Yat-sen University

Han Zhou

Sixth Affiliated Hospital of Sun Yat-sen University

Ying Jin

Sun Yat-sen University Cancer Center

\section{Feng Wang}

Sun Yat-sen University Cancer Center

\section{Qi Meng}

Sun Yat-sen University Cancer Center

\section{Yun-Le Wan}

Sixth Affiliated Hospital of Sun Yat-sen University

\section{Zhi-Zhong Pan}

Sun Yat-sen University Cancer Center

De-Shen Wang ( $\nabla$ wangdsh@sysucc.org.cn )

Sun Yat-sen University Cancer Center

\section{Research Article}

Keywords: colorectal liver metastases (CRLM), hepatectomy, lactate dehydrogenase (LDH), prognostic model, circulating biomarker

Posted Date: February 26th, 2021 
DOl: https://doi.org/10.21203/rs.3.rs-236654/v1

License: (c) (1) This work is licensed under a Creative Commons Attribution 4.0 International License. Read Full License 


\section{Abstract}

Background: The prognostic value of lactate dehydrogenase (LDH) in colorectal cancer patients has remained inconsistent between non-metastatic and metastatic settings. So far very few studies have included LDH in prognostic analysis for patients with colorectal liver metastases (CRLM) who underwent curative-intent hepatectomy.

Patients and Methods: Consecutive metastatic colorectal cancer patients who underwent curative-intent resection for CRLM from two Chinese medical centers treated in 2000-2019 were enrolled in the training cohort (434 patients) and the validation cohort (146 patients). Overall survival (OS) was the primary endpoint. Cox regression model was performed to identify the prognostic values of LDH and other clinicopathology variables. A modification of the established Fong scoring system comprising LDH was developed within this Chinese population.

Results: In the training cohort, preoperative LDH > upper limit of normal (ULN) was the strongest independent prognostic factor both for RFS (HR 2.11, 95\% confidence intervals [Cls], 1.54-2.89; $P<.001$ ) and OS (HR 2.41, 95\% Cl, 1.72-3.39; $P<.001)$ in multivariate analysis. 5-year survival rates were $23.7 \%$ and $52.9 \%$ in the LDH $>$ ULN group and LDH < ULN group, respectively. These data were also confirmed in the validation cohort and then in pooled cohort. Replacing carcinoembryonic antigen (CEA) with LDH in the Fong score contributed to an improvement in the predictive value.

Conclusions: Preoperative serum LDH is a reliable and independent predictor for curative-intent CRLM resection. Composite of LDH and Fong score is a potential stratification tool for CRLM resection.

\section{Introduction}

Colorectal cancer (CRC) is the third most common cancer and the second leading cause of cancer-related mortality worldwide [1-3]. The liver is the major life-limiting distant metastatic site for CRC [4]. About $20 \%-25 \%$ of CRC patients present concurrent liver metastases and over half will develop liver metastases through the course of diseases [5]. Surgical excision-based locoregional therapy remains the only possible curative option for colorectal liver metastases (CRLM) [6]. However, only about $20 \%$ of CRLM patients are candidates for curatively intended liver resection at diagnosis [7]. Whereas a growing number of curative hepatectomy has been achieved through multidisciplinary therapy within the latest decade, majority of patients $(50 \%-80 \%)$ would develop further recurrence $[8,9]$. Besides, the survival outcomes derived from different studies remain heterogeneous, with 5 -year survival rates ranging from $25 \%$ to $60 \%$ [10-12]. Thus, better selection of patients before initiating treatment is needed to refine the therapeutic decisions.

Recent studies have showed that apart from conditional clinicopathology variables (such as CEA and CA199 levels, KRAS and BRAF mutations, location and lymph node status of primary tumor, number and size of hepatic metastases, etc.), gene expression signatures, intratumoural immune cell infiltrations, and circulating tumor cells might also have prognostic impact for colorectal cancer $[10,11,13]$. In particular, 
the serum biochemical markers, namely Gamma-glutamyl transferase (GGT), alkaline phosphatase (ALP), and lactate dehydrogenase (LDH), are also gaining momentum as prognostic indicators for $\mathrm{mCRC}[14$, 15].

LDH is the key enzyme in aerobic and anaerobic glycolysis, it plays a pivotal role in tumor metabolism by mediating the conversion of pyruvate and lactate [16]. LDH levels have been confirmed to be closely related to hypoxia, angiogenesis, inflammatory and immune status in the tumor microenvironment (TME). High serum LDH levels indicate poor prognosis among various cancer entities [17-19]. Furthermore, so far very few studies have included LDH in prognostic analysis for patients with CRLM who underwent curative-intent hepatectomy. Therefore, it remains to be determined whether preoperative LDH levels could be used to predict patient outcome after complete CRLM resection when patients present no evidence of disease (NED).

To address this issue, we performed a two-center, retrospective observational study in a cohort of 580 metastatic colorectal cancer ( $\mathrm{mCRC}$ ) patients. Our objectives are to (a) evaluate the prognostic impact of preoperative serum LDH levels in CRLM patients who underwent curative-intent hepatectomy; and (b) integrate LDH into the established Fong scoring system within this Chinese population to improve patient stratification for CRLM resection.

\section{Materials And Methods}

\section{Study population}

This two-center, retrospective, cohort study enrolled 580 consecutive histologically proven CRLM patients who underwent curative-intent hepatectomy in Sun Yat-sen University Cancer Center (SYSUCC) and Sun Yat-sen University Sixth Affiliated Hospital (SYSUSAH). The prognostic impact of preoperative serum LDH levels in CRLM patients who undergo curative-intent hepatectomy was evaluated in the SYSUCC cohort (defined as the training cohort) and the SYSUSAP cohort (defined as the validation cohort). The SYSUCC cohort included 434 patients from September 2000 to December 2016, while the SYSUSAP cohort included 146 patients from August 2012 to June 2019. Detailed clinical information (pre- and postoperation clinicopathological data, blood examination, follow-up information, etc.) was retrieved from electronic and paper-based medical records from each center. To be eligible, the preoperative LDH value had to be available.

The major exclusion criteria were listed as follows: 1) Peritoneal metastasis; 2) history of previous hepatectomy; 3) R2 resection of liver metastases; 4) ablation of metastatic sites or transcatheter hepatic arterial chemoembolization (TACE) within 4 weeks of study entry; 5 ) patients in inflammatory conditions; 6) previous history of malignant tumor

The study was approved by the ethics committee of the SYSUCC and SYSUSAH and complied with the Declaration of Helsinki. 


\section{Follow-up}

Overall survival (OS) was defined as the time from the date of hepatic resection to the date of death from any cause or latest follow-up. Recurrence-free survival (RFS) was measured from the date of hepatic resection to the date of confirming recurrence or death from any cause, whichever occurred first. Patients were followed up through outpatient clinical visit or via telephone. The follow-up starts one month after operation and ends when tumor relapse or death was verified, while subjects who were lost or still alive at the date of last contact were considered as censored.

\section{Blood sample test}

Enrolled patients were divided into LDH-normal and LDH-high group, using the ULN (upper limit of normal) established by each center's laboratory as the cutoff value, in anticipation of elaborating a practical clinical tool for future use. The units used in measurement of LDH was U/L, and the ULN of LDH

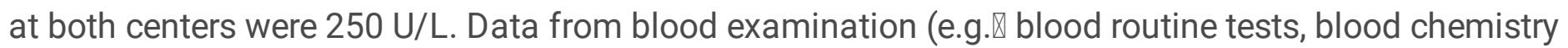
tests and tumor marker tests) were eligible for analysis if performed within 2 weeks before hepatectomy. Preoperative LDH levels, CEA levels, and immune/inflammation-related factors (including neutrophil, lymphocyte, monocyte, and platelet counts, LMR, LNR and LPR, and C-reaction protein) were collected. LMR, LNR and LPR was defined as absolute lymphocyte count divided by absolute monocyte, neutrophil and platelet count, respectively.

\section{Modified Clinical Risk Score (mCRS)establishment and validation}

The CRS was calculated according to the criteria initiated by Yuman Fong [20]. Briefly, five clinical criteria: primary lymph node positive, disease-free interval from the diagnosis of primary tumor $<12$ months, number of CRLM $>1$, maximum CRLM diameter $>5 \mathrm{~cm}$, preoperative CEA level $>200 \mathrm{ng} / \mathrm{ml}$, were assigned one point for each and total scores were defined as CRS.

We also established a modified CRS ( $m C R S$ ) model to better evaluate clinical benefit from hepatectomy of CRLM and the prognostic impact of LDH. Because preoperative CEA $>200 \mathrm{ng} / \mathrm{ml}$ was not significantly associated with OS in our patient group (details shown in Table 3), preoperative CEA level was replaced by LDH level (LDH > ULN was assigned one point) in the mCRS model. Then the patients were divided into low (0-1 points), intermediate (2-3 points) and high (4-5 points) risk group according to both models. The discriminatory ability of models was assessed by area under curve (AUC) in the time-dependent receiver operating characteristic (ROC) analysis. The Harrell's discrimination concordance index (C-index, which is defined as the probability that predictions and outcomes are concordant) was employed to validate the predictive ability of the models.

\section{Statistical analysis}

Patients' characteristics between different groups were compared with student's t-test, chi-square, Wilcoxon rank-sum test, or Kruskal-Wallis test as statistically appropriate. Survival curves were generated using the Kaplan-Meier method and compared with the log-rank test in terms of RFS and OS. 
OS was the primary endpoint and RFS was the secondary endpoint. In order to identify independent prognostic predictors, the association between baseline variables and survival was explored by Cox proportional hazard regression model, and quantified by hazard ratios (HRs) and corresponding 95\% confidence intervals (Cls). KRAS and BRAF mutation was not considered for Cox regression analysis because it was not available for all patients. But a sensitivity analysis in cases with available data of KRAS mutation status was performed in multivariable models.

Furthermore, subgroup analyses were carried out stratified by demographic and clinicopathologic variables, and presented by forest plots. In proportional hazard regression models, parameters with $P<$ 0.05 in the univariate analysis were selected and further included in the multivariate analysis, relying on the backward elimination algorithm with a selection level of 0.05 . In the multivariable analyses for pooled population, cohort was obligated to be an adjustment factor.

As for the comparison of time-dependent AUC between different models, the Wilcoxon matched-pair signed-rank test was applied. Time-dependent AUC was calculated by the Package timeROC (version 0.4). The C-index was calculated by the Package rms (version 5.1-3.1).

All $P$-values were calculated two-sided, and $P<0.05$ was considered statistically significant. Statistical analyses were conducted with the SPSS software version 19 (SPSS, Chicago, Illinois, USA), STATA (Release 14.2; StataCorp LP, College Station, TX) and GraphPad Prism 7.0.

\section{Results}

\section{Characteristics of patients}

580 consecutive CRLM patients who underwent curative-intent hepatectomy at two medical centers were enrolled. 434 patients were from SYSUCC and 146 patients were from SYSUSAH. Clinicopathology and treatment characteristics were listed in Table 1. All enrolled patients were Chinese individuals, average age at diagnosis was $59.6 \%$ of patients had CEA levels over $200 \mathrm{ng} / \mathrm{ml}$, while $16 \%$ of patients had LDH levels over ULN in in the whole population. The median follow-up time was 65.5 months in the SYSUCC (training) cohort and 42.1 months in the SYSUSAH (validation) cohort. OS was 59.5 months $(95 \% \mathrm{Cl}$, 58.4-70.6) in the pooled cohort, 58.9 months $(95 \% \mathrm{Cl}, 46.2-71.6)$ in the training cohort and 63.3 months $(95 \% \mathrm{Cl}, 61.3-67.8)$ in the validation cohort, respectively.

Overall, clinical features were well balanced between the two cohorts, except that patients in the training cohort had a higher proportion of synchronous CRLM (95\% vs $69 \%$ ), T4 stage of primary tumor ( $83 \%$ vs $64 \%$ ), well to moderately differentiated pathology ( $88 \%$ vs $76 \%$ ), and LDH levels above ULN ( $23 \%$ vs $14 \%$ ) than patients in the validation cohort.

\section{LDH levels and correlations with clinical characteristics}

The relationship between serum LDH and clinicopathological parameters was detailed in Table 2. In summary, serum LDH levels showed no statistical difference when stratified by demography 
characteristics (age, gender), primary tumor characteristics (tumor location, pathology differentiation, $\mathrm{T}$ and $\mathrm{N}$ stage, KRAS and BRAF mutation), and metastatic sites characteristics (presence of extrahepatic disease, number of CRLM, perioperative chemotherapy).

However, we observed that in the traning cohort, patients with maximum diameter of CRLM $>5 \mathrm{~cm}$ had a higher proportion of elevated LDH levels than patients with maximum diameter of CRLM $\leq 5 \mathrm{~cm}(36.2 \%$ vs $10.3 \%, P<.001)$. Patients with preoperative CEA $>200 \mathrm{ng} / \mathrm{ml}$ also had a greater possibility of having elevated LDH levels than those with CEA $\leq 200 \mathrm{ng} / \mathrm{ml}(29.6 \%$ vs $12.3 \%, P=0.018)$. In addition, patients with CRS of 4-5 had higher LDH levels than patients with CRS of 2-3 and 0-1 (LDH level > ULN, 42.3\% vs $13.1 \%$ vs $3.9 \% ; P<.001)$. While in the validation cohort, patients with left-sided primary tumor had a higher proportion of elevated LDH levels than those with right-sided primary tumor $(36.7 \%$ vs $13.3 \%, P=$ $0.021)$.

\section{Cox regression analysis of relapse-free survival and overall survival}

Univariate and multivariate Cox regression analyses were performed in the training and validation cohort, elevated preoperative LDH level (defined as LDH > ULN) was found to be the strongest prognostic factor both for RFS and OS.

In the training cohort, total five variables were identified as adverse prognostic makers for OS in the univariate analysis: lymph node metastases of primary tumor $(\mathrm{HR}, 1.77 ; 95 \% \mathrm{Cl}, 1.31-2.39 ; P<.001)$, number of $\mathrm{CRLM}>1(\mathrm{HR}, 1.85 ; 95 \% \mathrm{Cl}, 1.40-2.44 ; P<.001)$, maximum diameter of $\mathrm{CRLM}>5 \mathrm{~cm}(\mathrm{HR}, 2.17$; $95 \% \mathrm{Cl}, 1.53-3.08 ; P<.001)$, presence of extrahepatic disease (HR, 1.53; 95\% Cl, 1.03-2.27; $P=0.037)$, and preoperative LDH level > ULN (HR, 2.41; 95\% Cl, 1.72-3.39; $P<.001)$. The above variables were subsequently introduced in the multivariate analysis, and all remained their independent prognostic values after adjusted for clinicopathologic parameters (Table 3).

In the validation cohort, three variables were confirmed to correlate with OS both in univariate and multivariate analysis: LDH level > ULN (univariate HR, 3.16; 95\% Cl, 1.75-5.70; $P<.001$ ), lymph node metastases of primary tumor (univariate $\mathrm{HR}, 1.96 ; 95 \% \mathrm{Cl}, 1.03-3.76 ; P=0.042$ ), and T4 stage of primary tumor (univariate HR, 2.26; 95\% Cl, 1.17-4.37; $P=0.015$ ) (Supplementary Table 1). In pooled cohort, LDH level > ULN, lymph node metastases of primary tumor, number of CRLM, and maximum diameter of CRLM were independent predictors for OS in multivariate analysis (Supplementary Table 2).

In terms of RFS (supplementary Table 3), elevated LDH level (HR, 2.11;95\% Cl, 1.54-2.89; $P<.001$ ), lymph node metastases of primary tumor, number of CRLM $>1$, maximum diameter of CRLM $>5 \mathrm{~cm}$, presence of extrahepatic disease, and perioperative chemotherapy reversely correlated with RFS in the univariate analysis. While in the multivariate analysis, the first five variables remained independent predictive factors for RFS.

In the sensitivity analysis in cases with available data of $K R A S$ mutation status, only number of CRLM $>1$ was an independent predictor for OS in multivariable models, probably due to the limitation of sample 
size (Supplementary Table 4).

\section{Survival outcomes according to LDH levels and subgroups analysis}

RFS and OS was demonstrated by Kaplan-Meier curves according to LDH levels. In the training cohort, patients with LDH levels over the ULN had significantly shorter RFS ( 8.5 months vs 22.0 months; HR, 2.11; $95 \% \mathrm{Cl}, 1.54-2.89 ; P<.001)$ and OS (25.0 months vs 63.6 months; HR, $2.41,95 \% \mathrm{Cl}, 1.72-3.39 ; P<.001)$ than patients with LDH levels under the ULN, as shown in Fig. 1 and supplementary Fig. 1. Survival rates at 5 years in the LDH-normal and LDH-high group were $52.9 \%$ versus $23.7 \%$ in the training cohort, and $62.5 \%$ versus $30.9 \%$ in the validation cohort, respectively. The validation cohort and pooled cohort demonstrated similar results, patients with elevated LDH levels showed impaired OS compared with patients with normal LDH levels (Fig. 1B-1C).

The forest plots provided a clear trend that patients with LDH levels under the ULN obtained better survival benefit from hepatectomy for OS (Fig. 2) and RFS (supplementary Fig. 2). Subgroup analyses revealed that LDH produced consistent prognostic value across patient subgroups stratified by sex, age, preoperative CEA level, perioperative chemotherapy, primary tumor characteristics (location, lymph node status), liver metastases characteristics (number, maximum diameter, surgical margin, disease-free interval from primary tumor, extrahepatic disease), even by Fong score.

\section{Survival outcomes assessed by CRS model and modified CRS model}

OS stratified by different risk scores (0-5) as defined by CRS and mCRS was demonstrated by KaplanMeier curves in each cohort (Supplementary Fig. 3). Then we defined three risk groups as following: the low-risk group (CRS or mCRS 0-1), the intermediate-risk group (CRS or mCRS 2-3), and the high-risk group (CRS or mCRS 4-5). The CRS and modified CRS prognostic system were evaluated by three risk groups. The detailed survival results are shown according to each cohort (Table 4) and pooled cohort (Supplementary Table 5).

In the training cohort, median OS of the high-risk group in CRS and mCRS model were 26.1 months and 21.8 months, respectively, and those of the intermediate-risk group were both 49.0 months, while those in the low-risk group were both not reached after median follow up of 65.5 months (Fig. 3A-3B). Median RFS of the high-risk group in the CRS and mCRS model were 10.2 months and 8.3 months, respectively, and those of the intermediate-risk group were 14.2 months and 15.2 months, while those in the low-risk group were both not reached (Supplementary Fig. 4).

When applying CRS and mCRS models to the validation cohort (Fig. 3C-3D) and pooled cohort (Supplementary Fig. 5), the survival distributions showed the same trend as in the training cohort.

Receiver operating characteristic (ROC) analysis for the comparison of CRS and mCRS in prediction ability 
The modified Fong score, with a better prognostic discriminatory ability, outperformed the Fong score. Time-dependent ROC analysis displayed that the mCRS model exhibited a better predictive value than the CRS model in the training cohort, both for OS $(P=0.008)$ and RFS $(P=0.016)$. In the mCRS model, the Cindex of 5-year OS probability forecast was $0.641 \pm 0.026$, while the c-index of 24-months RFS probability forecast was $0.672 \pm 0.024$ (Fig. 4). In validation cohort, mCRS was numerically superior to the CRS in predicting OS evaluated by area under curve (AUC) in the time-dependent ROC analysis, though the $P$ value did not reach statistical significance (Supplementary Fig. 6). Particularly, compared to CRS, mCRS identified a relatively higher proportion of patients in the high-risk group (the training cohort, $9.8 \%$ vs $7.1 \%$; the validation cohort, $5.8 \%$ vs $2.2 \%$ ). Moreover, the median OS of patients in the high-risk group was numerically more discriminative in mCRS than in CRS (the training cohort, 21.8 vs 26.8 months; the validation cohort, 27.6 vs 44.8 months) (Table 4). These results suggest that replacing CEA with LDH in the CRS scoring system demonstrated a better accuracy.

\section{Association of LDH levels and immune/inflammation-related indexes}

In an exploratory analysis, it is interesting to note that LDH levels varied with a set of immune/inflammatory factors (Fig. 5). Specifically, patients with elevated LDH levels had higher preoperative neutrophil counts $(P=0.031)$, higher $C$-reaction protein (CRP) levels $(P<.001)$, and lower lymphocyte counts $(P=0.022)$ than patients with normal LDH levels. Consequently, patients with elevated LDH levels also had a lower lymphocyte-to-monocyte ratio (LMR; $P<.001)$ and lymphocyte-toneutrophil ratio $(\mathrm{LNR} ; P<.001)$. On the contrary, LDH level was not associated with preoperative total white blood cell counts or monocyte counts.

\section{Discussion}

In the current study, we found that LDH was the strongest prognostic factor in univariate and multivariate analysis both for RFS and OS. Patients with elevated levels of serum LDH had nearly three-fold higher risk for mortality. The 5 -year survival rate in the normal-LDH and high-LDH group was $52.9 \%$ versus $23.7 \%$ in the training cohort, and $62.5 \%$ versus $30.9 \%$ in the validation cohort, respectively (Fig. 1).

The prognostic value of LDH in CRC patients has remained inconsistent between non-metastatic and metastatic settings, especially between resectable and unresectable CRLM [21-23]. Elevated circulating LDH level was reported to be an adverse prognostic factor in unresectable CRLM patients receiving systemic therapy or hepatic arterial infusion [24-26]. Nevertheless, this effect was not obvious for the overall survival of nonmetastatic CRC patients $[27,28]$. To the best of our knowledge, our study is the first to address the independent prognostic impact of preoperative LDH levels in CRLM patients who undergo curative-intent hepatectomy.

The prognostic scoring system proposed by Fong et al has been widely used in clinical practice to stratify CRLM patients [20]. This five-marker prognostic scoring system consists of baseline CEA level $(200 \mathrm{ng} / \mathrm{ml}$ as cut-off value), lymph node status of the primary tumor, number and size of hepatic metastases, and disease-free interval from resection of primary tumor. Though routine CEA test in CRC care is 
recommended globally, in our dataset only $6.2 \%$ (27/411) of patients in the training cohort and $5.5 \%$ $(8 / 145)$ in the validation cohort had CEA $>200 \mathrm{ng} / \mathrm{ml}$, while a higher proportion of patients $(13.6 \%$ [59/435] and 15.9\% [34/204] in the corresponding cohort) had LDH over ULN. In accordance with a recent study [9], we found that CEA囚200 $\mathrm{ng} / \mathrm{ml}$ had insufficient statistical power to detect OS differences both in our training cohort $(P=0.373)$ and the validation cohort $(P=0.196)$ (Table 3 and Supplementary Table 1$)$. Notably, LDH could provide additional discriminatory ability on basis of CEA (Fig. 2). Specifically, among patients with CEA囚200 ng/ml, the OS (pooled cohort, OS 65.2 months vs 27.8 months, $P<.001$ ) and RFS (the training cohort, 22.0 months vs 9.0 months, $P<.001$ ) were distinguishable between patients with normal and elevated LDH levels. For patients with CEA $>200 \mathrm{ng} / \mathrm{ml}$, elevated LDH levels still indicated worse OS (pooled cohort, 25.9 months vs not reached, $P=0.012$ ) (Supplementary Fig. 7). Furthermore, replacing CEA with LDH in the CRS scoring system demonstrated a better discrimination ability. Particularly, mCRS could identify a relatively higher proportion of patients in the high-risk group than CRS (Table 4). Therefore, compared to CEA level, LDH could better define a portrait of the optimal candidate for CRLM resection with long-term survival, as well as a portrait of patients (e.g., for mCRS = 4-5) in whom direct hepatectomy may be ill-advised and further neoadjuvant or adjuvant systemic therapy would be preferable.

Evidence is emerging that increased LDH level is closely linked to hypoxia and angiogenesis in aggressive tumor phenotypes showing accelerated growth kinetics, and LDH is gaining momentum as an emerging anticancer target (liver, lung, bone, brain, etc.) [29-32]. CRLM can produce lactate and decrease the $\mathrm{pH}$ of tumor microenvironment (TME). Targeting CRLM metabolism provides a promising therapeutic approach to restore local NK-cell activity [33]. In TME, lactate may also inhibit the innate and adaptive immunity by promoting immune-suppressive proinflammatory cytokines such as TNF-a, IL-1, IL-6, prostaglandins, nuclear factor- $\mathrm{K} B$, recruiting tumor-associated macrophages (TAMs) and promoting their conversion into immunosuppressive (M2) phenotype [34, 35]. LDH therefore impacts the complex interplay between TME and host immune system, modulates tumor initiation, proliferation, invasion and migration potential [36].

In present study, serum LDH level did not show much relevance to various clinicopathological parameters (such as age, sex, primary tumor sidedness, $\mathrm{T}$ and $\mathrm{N}$ stage, KRAS and BRAF status, pathology differentiation and disease-free interval). Besides, the predictive effect of LDH was similar across different subgroups stratified by established prognostic factors (for instance, CEA levels, Fong score, etc.). Particularly, LDH could distinguish the survival regardless of surgical margin, the hazard ratios did not differ between R0 and non-R0 resection subset. LDH also demonstrated even stronger prognostic value among patients with extra-hepatic metastases (Fig. 2). It was reported that LDH could be the product of tumor necrosis due to hypoxia, which is a sign of high tumor burden [16]. In our analysis, elevated LDH level was indeed associated with the maximum diameter of liver metastatic site $\$ 5 \mathrm{~cm}$ (Table 2). Nevertheless, in fact, for patients with elevated LDH level, 31.4\% (11/35) of them had the maximum diameter of CRLM below median (pooled cohort, $2.35 \mathrm{~cm}$, data not shown). It was also worth noting that LDH level was not associated with the number of CRLM in both cohorts. Perhaps more importantly, subgroup analysis showed that the prognostic value of LDH was independent of the number and maximum size of CRLM (Fig. 2). The above findings suggest that the prognostic attributes of LDH in the 
current study goes beyond simple indicator of heavier tumor burden. High LDH level might denote an aggressive biology in a way that is independent of common molecular and clinicopathology status.

Interestingly, exploratory analysis unexpectedly showed that LDH level strongly correlated with systemic inflammation indexes, namely lymphocyte-to-monocyte ratio (LMR), lymphocyte-to-neutrophil ratio (LNR) and C-reaction protein (CRP). In contrast, this correlation was not observed for CEA levels (data not shown). It has been reported that systemic inflammation leads to lymphocytopenia and increased presence of TAMs, resulting in decreased cellular immunity [37-41]. Meanwhile, increasing data showed that LDH could be a marker of diminished antitumor immunity, and inversely correlate with response to immune checkpoint blockade therapy [42]. Moreover, hypoxia itself, or the overexpression of hypoxiaregulating factors such as HIF-1, Foxp3, CCL-28, may contribute to the formation of an immunosuppressive microenvironment by recruiting myeloid-derived suppressor cells (MDSCs) and TAMs $[43,44]$. Thus, the mechanisms or pathways regulating LDH may intersect with hypoxia and antitumor immunity $[16,33,35]$. LDH may serve as an alternative indicator of systemic inflammation and immunosuppression. Herein, we postulate that perioperative use of nonsteroidal ani-inflammatory drugs to reduce inflammation may decrease the risk of recurrence following hepatectomy [45].

We acknowledge that our analysis has some limitations due to its retrospective and observational nature. Some genetic parameters, including RAS, BRAF and microsatellite status, as well as post-relapse treatment, were not available in some datasets. It would be meaningful to combine LDH and specific mutations and molecular features of CRC (e.g., RAS, $B R A F$, microsatelite instability, tumor mutation burden, circulating tumor DNA) in the future. Recurrence time was not thoroughly recorded in the training cohort. Estimation of RFS was not stringently carried out at protocol-specified intervals, though most physicians assessed the tumor status every 8-12 weeks. Less frequent assessment may bias in favor of a longer RFS time. Nevertheless, this factor is less likely to influence the main OS outcomes, which could truly reflect the clinical benefit of hepatectomy [46].

Because determination of the optimal cutoff value of LDH was beyond the scope of this study, we used the ULN to dichotomize this continuous variable, and the two participating centers adopted the same ULN of $250 \mathrm{U} / \mathrm{ml}$. Finally, the enrollment dates for the two cohorts differed, and multidisciplinary prospectively defined resectability criteria were not established in the study protocol. The therapeutic decisions were made by a multi-disciplinary team (MDT) in the individual medical center. However, since surgical interventions might outline a selection process per se, this would minimize the variations in patient selection between the two cohorts.

Anyhow, the above weaknesses had to be seen through the lens of the clear strengths. The advantage of our study resided in the large sample size, the division in training and validation cohort, and the heterogeneous cohort of unselected, real-world patients. We also discovered that LDH might prove additional information on tumor metabolic and immune state. These findings, coupled with the accessibility and reproducibility of the noninvasive laboratory serum LDH test, endorsed its routine use in 
clinical practice. We expect future studies with prospective design to validate our results, as well as a more explicit understanding about the molecular mechanisms of LDH on governing tumor biology.

\section{Conclusion}

our study implicates LDH as a reliable and independent laboratory biomarker to predict clinical outcomes of CRLM patients undergo curative-intent hepatectomy. Integrating LDH into the established Fong scoring system can enhance the discrimination ability, potentially be used to improve patient stratification for CRLM resection.

\section{Abbreviations}

LDH, lactate dehydrogenase; ULN, upper limit of normal; CRLM, colorectal liver metastases; CRS, Clinical Risk Score; mCRS, modified Clinical Risk Score; HR, hazard ratio; $\mathrm{Cl}$, confidence interval; OS, overall survival; RFS, relapse-free survival; SYSUCC, Sun Yat-sen university cancer center; SYSUHAP, Sun Yat-sen university affiliated sixth hospital; AUC, area under curve.

\section{Declarations}

\section{Ethics approval and consent to participate}

The authors declare that ethical approval has been acquired from the Research Ethics Committee of Sun Yat-sen University Cancer Center and Sun Yat-sen University Sixth Affiliated Hospital for this retrospective analysis. All necessary informed consent required by applicable law has also been acquired from relevant patients. All methods were carried out in accordance with Helsinki guidelines. No further ethical approval was required.

\section{Consent for publication}

All authors have read and approved the final version to be published and signed the author disclosure form.

\section{Availability of data and materials}

The datasets used and/or analyzed during the current study are available from the corresponding author on reasonable request.

\section{Competing interests}

The authors declare that they have no conflicts of interest related to this research

\section{Funding}

This study was supported by National Natural Science Foundation of China (Grant No. 81802452, 82073302, 81602070, 81930065); Science and Technology Program of Guangzhou (2019B020227002, 
201904020046, 201803040019, 201704020228); China Postdoctoral Science Foundation (2019M653216).

\section{Authors' contributions}

DSW: conceptualization, project administration, and supervision. ZZP: data curation and resources. YLW: conceptualization, data curation, and resources. LB: writing - original draft, and writing - review and editing. ZYL: writing - original draft. YXL: writing - original draft, methodology, software, and visualization. QC: data curation and resources. HZ: data curation and resources. YJ: data curation and resources. FW: data curation and resources. QM: methodology, software, and visualization.

\section{Acknowledgements}

We acknowledge the invaluable contributions of the patients who participated in this study and their families. We are thankful to Dr Qi Zhao from Bionformatic Core of our center for the helpful comments on the data analysis.

\section{References}

1. Torre L, Bray F, Siegel R, Ferlay J, Lortet-Tieulent J, Jemal AJCacjfc: Global cancer statistics, 2012. CA Cancer J Clin 2015, 65(2):87-108.

2. Henley S, Ward E, Scott S, Ma J, Anderson R, Firth A, Thomas C, Islami F, Weir H, Lewis D et al: Annual report to the nation on the status of cancer, part l: National cancer statistics. cancer 2020, 126(10):2225-2249.

3. Feng RM, Zong YN, Cao SM, Xu RH: Current cancer situation in China: good or bad news from the 2018 Global Cancer Statistics? Cancer Commun (Lond) 2019, 39(1):22.

4. Alberts SR: Update on the optimal management of patients with colorectal liver metastases. Crit Rev Oncol Hematol 2012, 84(1):59-70.

5. Mella J, Biffin A, Radcliffe AG, Stamatakis JD, Steele RJ: Population-based audit of colorectal cancer management in two UK health regions. Colorectal Cancer Working Group, Royal College of Surgeons of England Clinical Epidemiology and Audit Unit. Br J Surg 1997, 84(12):1731-1736.

6. Ayez N, Burger JW, van der Pool AE, Eggermont AM, Grunhagen DJ, de Wilt JH, Verhoef C: Long-term results of the "liver first" approach in patients with locally advanced rectal cancer and synchronous liver metastases. Dis Colon Rectum 2013, 56(3):281-287.

7. Nordlinger B, Van Cutsem E, Gruenberger T, Glimelius B, Poston G, Rougier P, Sobrero A, Ychou M, European Colorectal Metastases Treatment G, Sixth International Colorectal Liver Metastases W: Combination of surgery and chemotherapy and the role of targeted agents in the treatment of patients with colorectal liver metastases: recommendations from an expert panel. Ann Onco/2009, 20(6):985-992. 
8. Kulaylat AN, Schubart JR, Stokes AL, Bhayani NH, Wong J, Kimchi ET, O'Carroll KF, Kaifi JT, Gusani $\mathrm{NJ}$ : Overall survival by pattern of recurrence following curative intent surgery for colorectal liver metastasis. J Surg Oncol 2014, 110(8):1011-1015.

9. Mavros M, Hyder O, Pulitano C, Aldrighetti L, Pawlik T: Survival of patients operated for colorectal liver metastases and concomitant extra-hepatic disease: external validation of a prognostic model. Journal of surgical oncology 2013, 107(5):481-485.

10. Tomlinson JS, Jarnagin WR, DeMatteo RP, Fong Y, Kornprat P, Gonen M, Kemeny N, Brennan MF, Blumgart LH, D'Angelica M: Actual 10-year survival after resection of colorectal liver metastases defines cure. J Clin Oncol 2007, 25(29):4575-4580.

11. Vigano L, Russolillo N, Ferrero A, Langella S, Sperti E, Capussotti L: Evolution of long-term outcome of liver resection for colorectal metastases: analysis of actual 5-year survival rates over two decades. Ann Surg Oncol 2012, 19(6):2035-2044.

12. Ayez N, Burger J, van der Pool A, Eggermont A, Grunhagen D, de Wilt J, Verhoef C: Long-term results of the "liver first" approach in patients with locally advanced rectal cancer and synchronous liver metastases. Diseases of the colon and rectum 2013, 56(3):281-287.

13. de Haas R, Wicherts D, Flores E, Azoulay D, Castaing D, Adam R: R1 resection by necessity for colorectal liver metastases: is it still a contraindication to surgery? Annals of surgery 2008, 248(4):626-637.

14. Hung HY, Chen JS, Chien Y, Tang R, Hsieh PS, Wen S, You YT, You JF, Chiang JM: Preoperative alkaline phosphatase elevation was associated with poor survival in colorectal cancer patients. Int J Colorectal Dis 2017, 32(12):1775-1778.

15. Abdel-Rahman O: Prognostic Value of Baseline ALBI Score Among Patients With Colorectal Liver Metastases: A Pooled Analysis of Two Randomized Trials. Clin Colorectal Cancer 2019, 18(1):e61e68.

16. Lukacova S, Sorensen BS, Alsner J, Overgaard J, Horsman MR: The impact of hypoxia on the activity of lactate dehydrogenase in two different pre-clinical tumour models. Acta Oncol 2008, 47(5):941947.

17. Kolev Y, Uetake H, Takagi Y, Sugihara K: Lactate dehydrogenase-5 (LDH-5) expression in human gastric cancer: association with hypoxia-inducible factor (HIF-1alpha) pathway, angiogenic factors production and poor prognosis. Ann Surg Oncol 2008, 15(8):2336-2344.

18. Gerlinger M, Wilson P, Powles T, Shamash J: Elevated LDH predicts poor outcome of recurrent germ cell tumours treated with dose dense chemotherapy. Eur J Cancer 2010, 46(16):2913-2918.

19. Yue ZX, Xing TY, Gao C, Liu SG, Zhao W, Zhao Q, Wang XS, Jin M, Ma XL: Chromosome band 11q23 deletion predicts poor prognosis in bone marrow metastatic neuroblastoma patients without MYCN amplification. Cancer Commun (Lond) 2019, 39(1):68.

20. Fong Y, Fortner J, Sun RL, Brennan MF, Blumgart LH: Clinical score for predicting recurrence after hepatic resection for metastatic colorectal cancer: analysis of 1001 consecutive cases. Ann Surg 1999, 230(3):309-318; discussion 318-321. 
21. Wu XZ, Ma F, Wang XL: Serological diagnostic factors for liver metastasis in patients with colorectal cancer. World J Gastroenterol 2010, 16(32):4084-4088.

22. Connell LC, Boucher TM, Chou JF, Capanu M, Maldonado S, Kemeny NE: Relevance of CEA and LDH in relation to KRAS status in patients with unresectable colorectal liver metastases. J Surg Oncol 2017, 115(4):480-487.

23. Chibaudel B, Bonnetain F, Tournigand C, Bengrine-Lefevre L, Teixeira L, Artru P, Desrame J, Larsen AK, Andre T, Louvet $C$ et al: Simplified prognostic model in patients with oxaliplatin-based or irinotecanbased first-line chemotherapy for metastatic colorectal cancer: a GERCOR study. Oncologist 2011, 16(9):1228-1238.

24. Lin J, Peng J, Zhao Y, Luo B, Zhao Y, Deng Y, Sui Q, Gao Y, Zeng Z, Lu Z et al: Early recurrence in patients undergoing curative resection of colorectal liver oligometastases: identification of its clinical characteristics, risk factors, and prognosis. J Cancer Res Clin Oncol 2018, 144(2):359-369.

25. Giessen C, Fischer von Weikersthal L, Laubender RP, Stintzing S, Modest DP, Schalhorn A, Schulz C, Heinemann V: Evaluation of prognostic factors in liver-limited metastatic colorectal cancer: a preplanned analysis of the FIRE-1 trial. Br J Cancer 2013, 109(6):1428-1436.

26. Lisanti C, Basile D, Parnofiello A, Bertoli E, Andreotti V, Garattini S, Bartoletti M, Cattaneo M, Di Nardo $\mathrm{P}, \mathrm{Bonotto} \mathrm{M}$ et al: The SENECA study: Prognostic role of serum biomarkers in older patients with metastatic colorectal cancer. Journal of geriatric oncology 2020.

27. Li G, Wang Z, Xu J, Wu H, Cai S, He Y: The prognostic value of lactate dehydrogenase levels in colorectal cancer: a meta-analysis. BMC Cancer 2016, 16(1).

28. Caputo D, Caricato M, Vincenzi B, La Vaccara V, Mascianà G, Coppola R: Serum lactate dehydrogenase alone is not a helpful prognostic factor in resected colorectal cancer patients. Updates in surgery 2014, 66(3):211-215.

29. Koukourakis MI, Giatromanolaki A, Simopoulos C, Polychronidis A, Sivridis E: Lactate dehydrogenase 5 (LDH5) relates to up-regulated hypoxia inducible factor pathway and metastasis in colorectal cancer. Clin Exp Metastasis 2005, 22(1):25-30.

30. Scartozzi M, Giampieri R, Maccaroni E, Del Prete M, Faloppi L, Bianconi M, Galizia E, Loretelli C, Belvederesi L, Bittoni A et al: Pre-treatment lactate dehydrogenase levels as predictor of efficacy of first-line bevacizumab-based therapy in metastatic colorectal cancer patients. British journal of cancer 2012, 106(5):799-804.

31. Loupakis F, Intini R, Cremolini C, Orlandi A, Sartore-Bianchi A, Pietrantonio F, Pella N, Spallanzani A, Dell'Aquila E, Scartozzi M et al: A validated prognostic classifier for BRAF-mutated metastatic colorectal cancer: the 'BRAF BeCool' study. European journal of cancer (Oxford, England : 1990) 2019, 118:121-130.

32. Kemeny N, Braun D: Prognostic factors in advanced colorectal carcinoma. Importance of lactic dehydrogenase level, performance status, and white blood cell count. The American journal of medicine 1983, 74(5):786-794. 
33. Li F, Zhan L, Dong Q, Wang Q, Wang Y, Li X, Zhang Y, Zhang J: Tumor-Derived Exosome-Educated Hepatic Stellate Cells Regulate Lactate Metabolism of Hypoxic Colorectal Tumor Cells via the IL6/STAT3 Pathway to Confer Drug Resistance. OncoTargets and therapy 2020, 13:7851-7864.

34. Basile D, Garattini SK, Corvaja C, Montico M, Cortiula F, Pelizzari G, Gerratana L, Audisio M, Lisanti C, Fanotto V et al: The MIMIC Study: Prognostic Role and Cutoff Definition of Monocyte-to-Lymphocyte Ratio and Lactate Dehydrogenase Levels in Metastatic Colorectal Cancer. Oncologist 2020.

35. Van Wilpe S, Koornstra R, Den Brok M, De Groot JW, Blank C, De Vries J, Gerritsen W, Mehra N: Lactate dehydrogenase: a marker of diminished antitumor immunity. Oncoimmunology 2020, 9(1):1731942.

36. Graziano F, Ruzzo A, Giacomini E, Ricciardi T, Aprile G, Loupakis F, Lorenzini P, Ongaro E, Zoratto F, Catalano $\mathrm{V}$ et al: Glycolysis gene expression analysis and selective metabolic advantage in the clinical progression of colorectal cancer. The pharmacogenomics journal 2017, 17(3):258-264.

37. Terzic J, Grivennikov S, Karin E, Karin M: Inflammation and colon cancer. Gastroenterology 2010, 138(6):2101-2114 e2105.

38. Køstner A, Kersten C, Löwenmark T, Ydsten K, Peltonen R, Isoniemi H, Haglund C, Gunnarsson U, Isaksson $\mathrm{B}$ : The prognostic role of systemic inflammation in patients undergoing resection of colorectal liver metastases: C-reactive protein (CRP) is a strong negative prognostic biomarker. Journal of surgical oncology 2016, 114(7):895-899.

39. Haruki K, Shiba H, Horiuchi T, Sakamoto T, Gocho T, Fujiwara Y, Furukawa K, Misawa T, Yanaga K: Impact of the C-reactive protein to albumin ratio on long-term outcomes after hepatic resection for colorectal liver metastases. Am J Surg 2017, 214(4):752-756.

40. Okugawa Y, Toiyama Y, Yamamoto A, Shigemori T, Ide S, Kitajima T, Fujikawa H, Yasuda H, Hiro J, Yoshiyama S et al: Lymphocyte-C-reactive Protein Ratio as Promising New Marker for Predicting Surgical and Oncological Outcomes in Colorectal Cancer. Annals of surgery 2020, 272(2):342-351.

41. Diakos $\mathrm{Cl}$, Charles KA, McMillan DC, Clarke SJ: Cancer-related inflammation and treatment effectiveness. Lancet Oncol 2014, 15(11):e493-503.

42. Koh YW, Kang HJ, Park C, Yoon DH, Kim S, Suh C, Go H, Kim JE, Kim CW, Huh J: The ratio of the absolute lymphocyte count to the absolute monocyte count is associated with prognosis in Hodgkin's lymphoma: correlation with tumor-associated macrophages. Oncologist 2012, 17(6):871880 .

43. Liu Q, Luo D, Cai S, Li Q, Li X: Circulating basophil count as a prognostic marker of tumor aggressiveness and survival outcomes in colorectal cancer. Clinical and translational medicine 2020, 9(1):6.

44. Ding J, Karp JE, Emadi A: Elevated lactate dehydrogenase (LDH) can be a marker of immune suppression in cancer: Interplay between hematologic and solid neoplastic clones and their microenvironments. Cancer Biomark 2017, 19(4):353-363.

45. Schack A, Fransgaard T, Klein MF, Gögenur I: Perioperative Use of Nonsteroidal Anti-inflammatory Drugs Decreases the Risk of Recurrence of Cancer After Colorectal Resection: A Cohort Study Based 
on Prospective Data. Annals of Surgical Oncology 2019, 26(12):3826-3837.

46. Pilz L, Manegold C, Schmid-Bindert G: Statistical considerations and endpoints for clinical lung cancer studies: Can progression free survival (PFS) substitute overall survival (OS) as a valid endpoint in clinical trials for advanced non-small-cell lung cancer? Translational lung cancer research 2012, 1(1):26-35.

\section{Tables}

Table 1. Patient Clinicopathologic Characteristics 


\begin{tabular}{|c|c|c|c|c|}
\hline \multirow[t]{2}{*}{ Characteristics } & Pooled cohort & Training cohort & Validation cohort & \multirow{2}{*}{$\begin{array}{l}P \\
\text { value }^{a}\end{array}$} \\
\hline & $\mathrm{n}(\%)$ & $\mathrm{n}(\%)$ & $\mathrm{n}(\%)$ & \\
\hline \multicolumn{5}{|l|}{ Patient characteristics } \\
\hline Age: median (range) & $59(20-82)$ & $57(20-82)$ & $59(24-80)$ & 0.507 \\
\hline Gender & & & & 1.000 \\
\hline Male & $385(66.4)$ & $288(66.4)$ & $97(66.4)$ & \\
\hline Female & $195(33.6)$ & $146(33.6)$ & $49(33.6)$ & \\
\hline Preoperative CEA & & & & 0.843 \\
\hline$>200 \mathrm{ng} / \mathrm{ml}$ & $35(6.3)$ & $27(6.6)$ & $8(5.5)$ & \\
\hline$\leq 200 \mathrm{ng} / \mathrm{ml}$ & $520(93.7)$ & $383(93.4)$ & $137(94.5)$ & \\
\hline Preoperative LDH & & & & 0.009 \\
\hline Over ULN & $93(16.0)$ & $59(13.6)$ & $34(23.3)$ & \\
\hline Under ULN & $487(84.0)$ & $375(86.4)$ & $112(76.7)$ & \\
\hline \multicolumn{5}{|l|}{ Survival outcomes } \\
\hline $\begin{array}{l}\text { Median follow-up } \\
\text { (month) }\end{array}$ & $\begin{array}{l}60.5(95 \% \mathrm{Cl}, 57.5- \\
63.5)\end{array}$ & $\begin{array}{l}65.5(95 \% \mathrm{Cl}, 61.7- \\
69.3)\end{array}$ & $\begin{array}{l}42.1(95 \% \mathrm{Cl}, 36.7- \\
47.5)\end{array}$ & - \\
\hline OS (month) & $\begin{array}{l}59.5(95 \% \mathrm{Cl}, 58.4- \\
70.6)\end{array}$ & $\begin{array}{l}58.9(95 \% \mathrm{Cl}, 46.2- \\
71.6)\end{array}$ & $\begin{array}{l}63.3(95 \% \mathrm{Cl}, 61.3- \\
67.8)\end{array}$ & 0.444 \\
\hline \multicolumn{5}{|l|}{$\begin{array}{l}\text { Primary tumor } \\
\text { characteristics }\end{array}$} \\
\hline Location ${ }^{b}$ & & & & 0.231 \\
\hline Right-sided & $139(29.0)$ & $109(32.3)$ & $30(20.5)$ & \\
\hline Left-sided & $340(71.0)$ & $224(67.3)$ & $116(79.5)$ & \\
\hline Differentiation & & & & 0.003 \\
\hline Well/moderate & $459(79.1)$ & $331(76.3)$ & $128(87.7)$ & \\
\hline Poor & $121(20.9)$ & $103(23.7)$ & $18(12.3)$ & \\
\hline T stage & & & & $<.001$ \\
\hline Non-T4 & $377(69.0)$ & $258(64.0)$ & $119(83.2)$ & \\
\hline T4 & $169(31.0)$ & $145(36.0)$ & $24(16.8)$ & \\
\hline $\begin{array}{l}\text { Lymph node } \\
\text { metastases }\end{array}$ & & & & 0.313 \\
\hline
\end{tabular}




\begin{tabular}{|c|c|c|c|c|}
\hline Absent & $197(39.2)$ & $146(40.6)$ & $51(35.6)$ & \\
\hline Present & $305(60.8)$ & $213(59.4)$ & $92(64.4)$ & \\
\hline \multicolumn{5}{|c|}{ CRLM characteristics } \\
\hline \multicolumn{2}{|c|}{ Largest metastasis site } & & & 0.578 \\
\hline$\leq 5 \mathrm{~cm}$ & $490(86.0)$ & $370(86.4)$ & $120(84.5)$ & \\
\hline$>5 \mathrm{~cm}$ & $80(14.0)$ & $58(13.6)$ & $22(15.5)$ & \\
\hline \multicolumn{2}{|c|}{ Number of metastases } & & & 0.264 \\
\hline $1-2$ & $388(66.9)$ & $296(68.2)$ & $92(63.0)$ & \\
\hline$>2$ & $192(33.1)$ & $138(31.8)$ & $54(37.0)$ & \\
\hline \multicolumn{2}{|c|}{ Metastatic interval } & & & $<.001$ \\
\hline Synchronous & $440(75.9)$ & $301(69.4)$ & $139(95.2)$ & \\
\hline Metachronous & $140(24.1)$ & $133(30.6)$ & $7(4.8)$ & \\
\hline \multicolumn{2}{|l|}{$\mathrm{R} 0$ resection } & & & 0.190 \\
\hline Yes & $504(87.5)$ & $388(89.4)$ & $116(81.7)$ & \\
\hline No & $72(12.5)$ & $46(10.6)$ & $26(18.3)$ & \\
\hline
\end{tabular}

a Patient characteristic was compared between the training cohort and the validation cohort. ${ }^{b}$ Colorectal cancer arising in or proximal to the splenic flexure were defined as right-sided, and those arising distal to the splenic flexure were defined as left-sided.

Abbreviations: LDH, lactate dehydrogenase; ULN, upper limit of normal; CRLM, colorectal liver metastases.

Table 2. Relation between patient clinical characteristics and LDH levels 


\begin{tabular}{|c|c|c|c|c|c|c|}
\hline \multirow{4}{*}{ Characteristics } & \multicolumn{3}{|c|}{ Training cohort } & \multicolumn{3}{|c|}{ Validation cohort } \\
\hline & \multicolumn{2}{|l|}{ LDH level } & \multirow{3}{*}{$\begin{array}{l}P \\
\text { value }\end{array}$} & \multicolumn{2}{|l|}{ LDH level } & \multirow{3}{*}{$\begin{array}{l}P \\
\text { value }\end{array}$} \\
\hline & $\begin{array}{l}\text { Under } \\
\text { ULN }\end{array}$ & $\begin{array}{l}\text { Over } \\
\text { ULN }\end{array}$ & & $\begin{array}{l}\text { Under } \\
\text { ULN }\end{array}$ & $\begin{array}{l}\text { Over } \\
\text { ULN }\end{array}$ & \\
\hline & n (\%) & $\mathrm{n}(\%)$ & & n (\%) & $\mathrm{n}(\%)$ & \\
\hline \multicolumn{7}{|c|}{ Patient Characteristics } \\
\hline Age & & & 0.666 & & & 0.430 \\
\hline$\leq 60$ & $\begin{array}{l}235 \\
(87.0)\end{array}$ & $\begin{array}{l}35 \\
(13.0)\end{array}$ & & $71(78.9)$ & $19(21.1)$ & \\
\hline$>60$ & $\begin{array}{l}140 \\
(85.4)\end{array}$ & $\begin{array}{l}24 \\
(14.6)\end{array}$ & & $41(73.2)$ & $15(26.8)$ & \\
\hline Gender & & & 0.237 & & & 0.837 \\
\hline Male & $\begin{array}{l}253 \\
(87.8)\end{array}$ & $\begin{array}{l}35 \\
(12.2)\end{array}$ & & 75 (77.3) & $22(22.7)$ & \\
\hline Female & $\begin{array}{l}122 \\
(83.6)\end{array}$ & $\begin{array}{l}24 \\
(13.6)\end{array}$ & & $37(75.5)$ & $12(24.5)$ & \\
\hline Preoperative CEA & & & 0.018 & & & 0.079 \\
\hline$\leq 200 \mathrm{ng} / \mathrm{ml}$ & $\begin{array}{l}336 \\
(87.7)\end{array}$ & $\begin{array}{l}47 \\
(12.3)\end{array}$ & & $\begin{array}{l}108 \\
(78.8)\end{array}$ & $29(21.2)$ & \\
\hline$>200 \mathrm{ng} / \mathrm{ml}$ & $19(70.4)$ & $8(29.6)$ & & $4(50.0)$ & $4(50.0)$ & \\
\hline \multicolumn{7}{|l|}{$\begin{array}{l}\text { Primary tumor } \\
\text { characteristics }\end{array}$} \\
\hline Location ${ }^{a}$ & & & 0.702 & & & 0.021 \\
\hline Right-sided & $94(86.2)$ & $\begin{array}{l}15 \\
(13.8)\end{array}$ & & $26(86.7)$ & $4(13.3)$ & \\
\hline Left-sided & $\begin{array}{l}140 \\
(88.1)\end{array}$ & $\begin{array}{l}19 \\
(11.9)\end{array}$ & & $31(63.3)$ & $18(36.7)$ & \\
\hline Differentiation & & & 0.411 & & & 0.766 \\
\hline Well/moderate & $\begin{array}{l}283 \\
(85.5)\end{array}$ & $\begin{array}{l}48 \\
(14.5)\end{array}$ & & $99(77.3)$ & $29(22.7)$ & \\
\hline Poor & $92(89.3)$ & $\begin{array}{l}11 \\
(10.7)\end{array}$ & & $13(72.2)$ & $5(27.8)$ & \\
\hline T stage & & & 0.362 & & & 0.292 \\
\hline Non-T4 & $\begin{array}{l}227 \\
(88.0)\end{array}$ & $\begin{array}{l}31 \\
(12.0)\end{array}$ & & 93 (78.2) & $26(21.8)$ & \\
\hline
\end{tabular}




\begin{tabular}{|c|c|c|c|c|c|c|}
\hline T4 & $\begin{array}{l}123 \\
(84.8)\end{array}$ & $\begin{array}{l}22 \\
(15.2)\end{array}$ & & $16(66.7)$ & $8(33.3)$ & \\
\hline Lymph node metastases & & & 0.085 & & & 1.000 \\
\hline Absent & $\begin{array}{l}132 \\
(90.4)\end{array}$ & $14(9.6)$ & & $39(76.5)$ & $12(23.5)$ & \\
\hline Present & $\begin{array}{l}179 \\
(84.0)\end{array}$ & $\begin{array}{l}34 \\
(16.0)\end{array}$ & & $70(76.1)$ & $22(23.9)$ & \\
\hline KRAS & & & 0.780 & & & \\
\hline Wild type & $52(82.5)$ & $\begin{array}{l}11 \\
(17.5)\end{array}$ & & & & \\
\hline Mutation & $31(86.1)$ & $5(13.9)$ & & & & \\
\hline$B R A F$ & & & 0.318 & & & \\
\hline Wild type & $47(83.9)$ & $9(16.1)$ & & & & \\
\hline Mutation & $1(50.0)$ & $1(50.0)$ & & & & \\
\hline \multicolumn{7}{|l|}{ CRLM characteristics } \\
\hline Largest metastasis site & & & $<.001$ & & & 0.001 \\
\hline$\leq 5 \mathrm{~cm}$ & $\begin{array}{l}332 \\
(89.7)\end{array}$ & $\begin{array}{l}38 \\
(10.3)\end{array}$ & & $98(81.7)$ & $22(18.3)$ & \\
\hline$>5 \mathrm{~cm}$ & $37(63.8)$ & $\begin{array}{l}21 \\
(36.2)\end{array}$ & & $10(45.5)$ & $12(54.5)$ & \\
\hline Number of metastases & & & 0.125 & & & 0.685 \\
\hline $1-2$ & $\begin{array}{l}262 \\
(88.5)\end{array}$ & $\begin{array}{l}34 \\
(11.5)\end{array}$ & & $72(78.3)$ & $20(21.7)$ & \\
\hline$>2$ & $\begin{array}{l}113 \\
(81.9)\end{array}$ & $\begin{array}{l}25 \\
(18.1)\end{array}$ & & $40(74.1)$ & $14(25.9)$ & \\
\hline Metastatic interval & & & 0.229 & & & 0.201 \\
\hline Synchronous & $\begin{array}{l}256 \\
(85.0)\end{array}$ & $\begin{array}{l}45 \\
(15.0)\end{array}$ & & $\begin{array}{l}105 \\
(75.5)\end{array}$ & $34(24.5)$ & \\
\hline Metachronous & $\begin{array}{l}119 \\
(85.0)\end{array}$ & $\begin{array}{l}14 \\
(15.0)\end{array}$ & & $7(100.0)$ & $0(0.00)$ & \\
\hline Extrahepatic disease & & & 0.512 & & & \\
\hline Absent & $\begin{array}{l}334 \\
(86.8)\end{array}$ & $\begin{array}{l}51 \\
(13.2)\end{array}$ & & & & \\
\hline Present & $41(83.7)$ & $8(16.3)$ & & & & \\
\hline Perioperative Chemotherapy & & & 0.467 & & & \\
\hline
\end{tabular}




\begin{tabular}{|c|c|c|c|c|c|}
\hline Yes & $\begin{array}{l}309 \\
(87.0)\end{array}$ & $\begin{array}{l}46 \\
(13.0)\end{array}$ & & & \\
\hline No & 66 (83.5) & $\begin{array}{l}13 \\
(16.5)\end{array}$ & & & \\
\hline CRS & & & & & 0.411 \\
\hline $0-1$ & $73(96.1)$ & $3(3.9)$ & $60(80.0)$ & 15 (20.0) & \\
\hline $2-3$ & $\begin{array}{l}233 \\
(86.9)\end{array}$ & $\begin{array}{l}35 \\
(13.1)\end{array}$ & $43(70.5)$ & $18(29.5)$ & \\
\hline $4-5$ & 15 (57.7) & $\begin{array}{l}11 \\
(42.3)\end{array}$ & $2(66.7)$ & 1 (33.3) & \\
\hline
\end{tabular}

${ }^{a}$ Colorectal cancer arising in or proximal to the splenic flexure were defined as right-sided, and those arising

distal to the splenic flexure were defined as left-sided. Abbreviations: LDH, lactate dehydrogenase; ULN, upper limit of normal; CRLM, colorectal liver metastases; $\quad$ CRS, Clinical Risk Score Table 3. Univariate and multivariate analyses for predictors of overall survival in the training cohort 


\begin{tabular}{|c|c|c|c|c|}
\hline \multirow[b]{2}{*}{ Variables } & \multicolumn{2}{|c|}{ Univariate analysis } & Multivariate analysis & \multirow[b]{2}{*}{$P$ value } \\
\hline & $\mathrm{HR}(95 \% \mathrm{Cl})$ & $P$ value & $\mathrm{HR}(95 \% \mathrm{Cl})$ & \\
\hline Age $(>60)$ & $1.25(0.95-1.64)$ & 0.105 & & \\
\hline Gender (male) & $1.31(0.98-1.75)$ & 0.068 & & \\
\hline \multicolumn{5}{|l|}{ Primary tumor location } \\
\hline Right-sided vs. left-sided & $1.06(0.78-1.45)$ & 0.704 & & \\
\hline Rectum vs. colon & $1.22(0.93-1.59)$ & 0.153 & & \\
\hline Poor differentiation & $1.20(0.89-1.63)$ & 0.258 & & \\
\hline T stage (T4) & $1.18(0.89-1.57)$ & 0.263 & & \\
\hline Lymph node metastases & $1.77(1.31-2.39)$ & $<.001$ & $1.71(1.26-2.33)$ & 0.001 \\
\hline Preoperative CEA (> 200ng/ml) & $1.27(0.75-2.15)$ & 0.373 & & \\
\hline Perioperative chemotherapy & $1.11(0.76-1.61)$ & 0.590 & & \\
\hline Metachronous CRLM & $0.86(0.65-1.15)$ & 0.307 & & \\
\hline $\begin{array}{l}\text { Number of liver metastases } \\
(>1)\end{array}$ & $1.85(1.40-2.44)$ & $<.001$ & $1.71(1.28-2.27)$ & $<.001$ \\
\hline Largest metastasis $(>5 \mathrm{~cm})$ & $2.17(1.53-3.08)$ & $<.001$ & $1.78(1.24-2.54)$ & 0.002 \\
\hline Extrahepatic disease (Yes) & $1.53(1.03-2.27)$ & 0.037 & $1.53(1.01-2.30)$ & 0.043 \\
\hline LDH level (above ULN) & $2.41(1.72-3.39)$ & $<.001$ & $2.07(1.46-2.94)$ & $<.001$ \\
\hline
\end{tabular}

Abbreviations: $\mathrm{HR}$, hazard ratio; $\mathrm{Cl}$, confidence interval; $\mathrm{CRLM}$, colorectal liver metastases; ULN, upper limit of normal.

Table 4. Survival outcomes according to Clinical Risk Score and modified Clinical Risk Score 


\begin{tabular}{|cllll|}
\hline \multicolumn{3}{|c}{ Training cohort } & \multicolumn{3}{c|}{ Validation cohort } \\
\hline Risk score & $\begin{array}{l}\text { Median OS } \\
\text { months }(95 \% \mathrm{Cl})\end{array}$ & $\mathrm{HR}(95 \% \mathrm{Cl})$ & $\begin{array}{l}\text { Median OS } \\
\text { months }(95 \% \mathrm{Cl})\end{array}$ & $\mathrm{HR}(95 \% \mathrm{Cl})$ \\
\hline CRS & & & & \\
\hline $0-1$ & not reached & 1.00 & not reached & 1.00 \\
\hline $2-3$ & $49.0(37.5-60.6)$ & $2.41(1.55-3.74)$ & $40.7(20.7-60.8)$ & $1.98(1.10-3.59)$ \\
\hline $4-5$ & $26.1(16.8-35.4)$ & $2.18(1.60-2.97)$ & $44.8(5.2-84.5)$ & $1.64(0.89-3.04)$ \\
\hline mCRS & & & & \\
\hline $0-1$ & not reached & 1.00 & not reached & 1.00 \\
\hline $2-3$ & $49.0(36.8-61.3)$ & $2.60(1.66-4.07)$ & $40.7(22.3-59.2)$ & $2.23(1.20-4.14)$ \\
\hline $4-5$ & $21.8(12.6-31.1)$ & $2.43(1.82-3.24)$ & $27.6(18.1-37.0)$ & $2.02(1.25-3.25)$ \\
\hline
\end{tabular}

Abbreviations: HR, hazard ratio; $\mathrm{Cl}$, confidence interval; OS, overall survival; CRS, Clinical Risk Score; mCRS, modified Clinical Risk Score.

Figures 
Training cohort
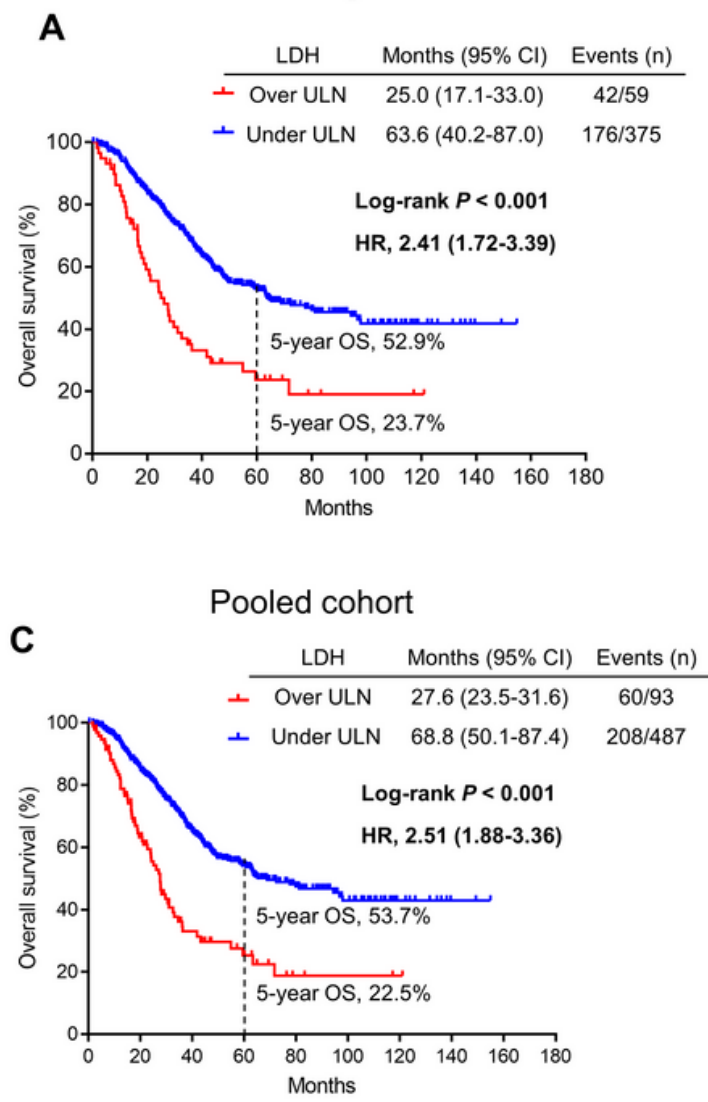

Validation cohort

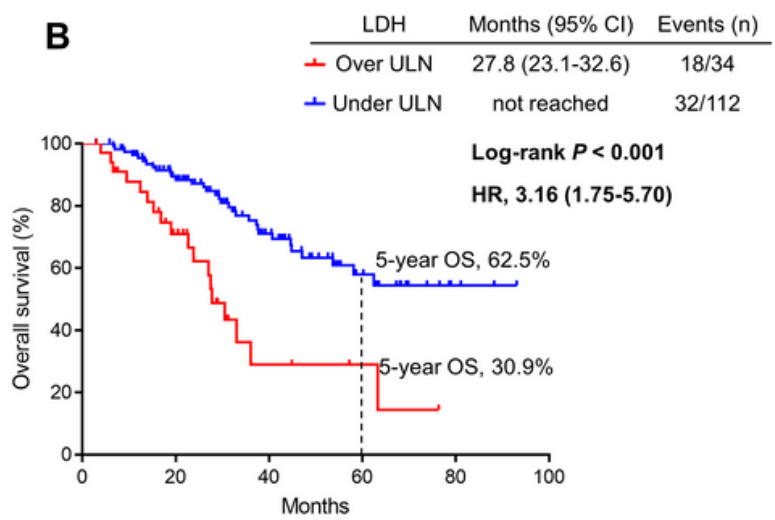

\section{Figure 1}

Survival outcomes according to LDH levels estimated by Kaplan-Meier curves. (A) Overall survival stratified by LDH levels in the training cohort. (A-B) Overall survival stratified by LDH levels in the SYSUCC cohort and SYSUSAH cohort. (C) Overall survival stratified by LDH levels in pooled cohort. Abbreviations: LDH, lactate dehydrogenase; ULN, upper limit of normal; $\mathrm{Cl}$, confidence interval; HR, hazard ratio. 


\section{SYSUCC cohort}

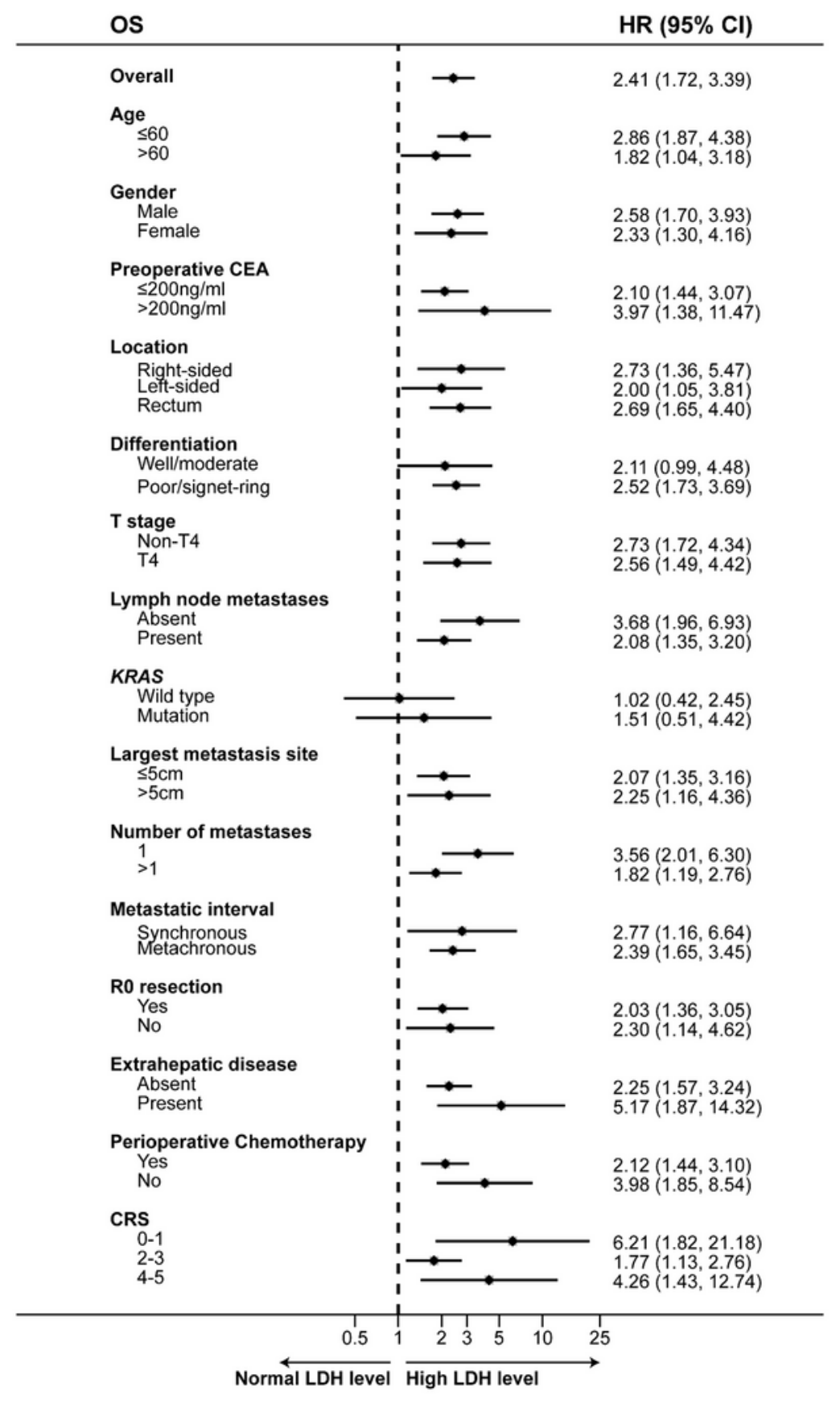

\section{Figure 2}

Forest plots of hazard ratios (elevated LDH levels versus normal LDH levels) for overall survival according to subgroups in the SYSUCC cohort. Abbreviations: OS, overall survival; RFS, relapse-free survival; HR, hazard ratio; CRS, Clinical Risk Score. 
A

Training cohort

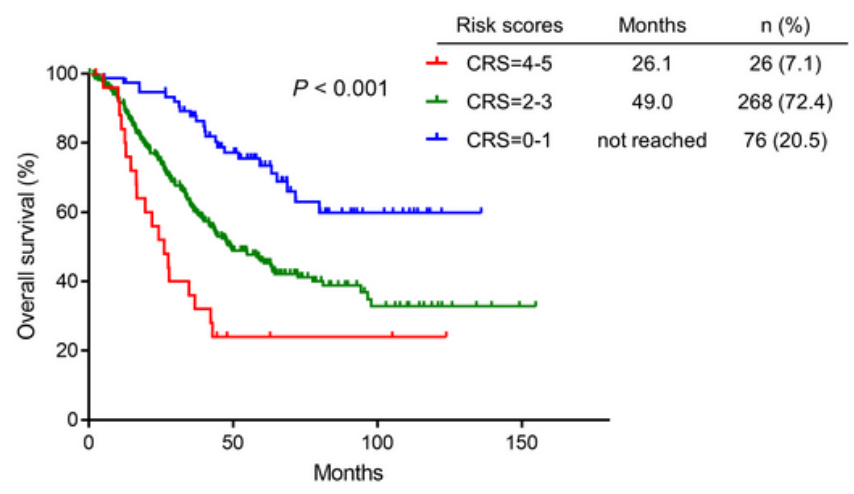

C

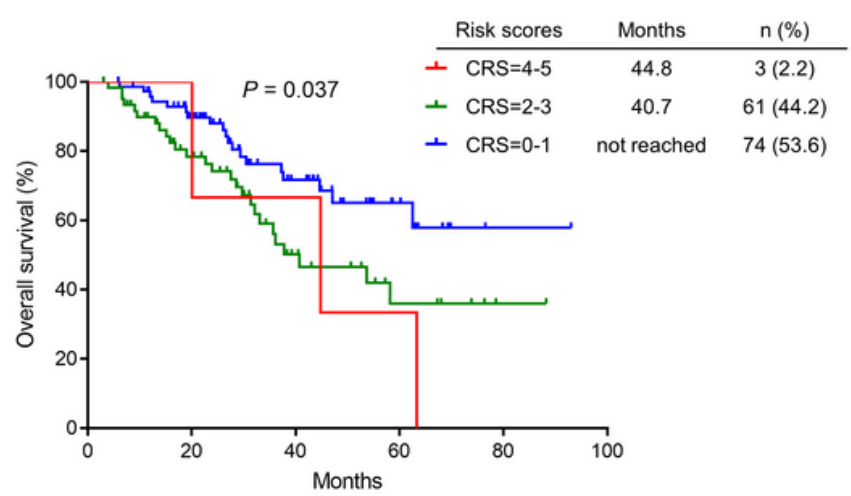

B

Training cohort

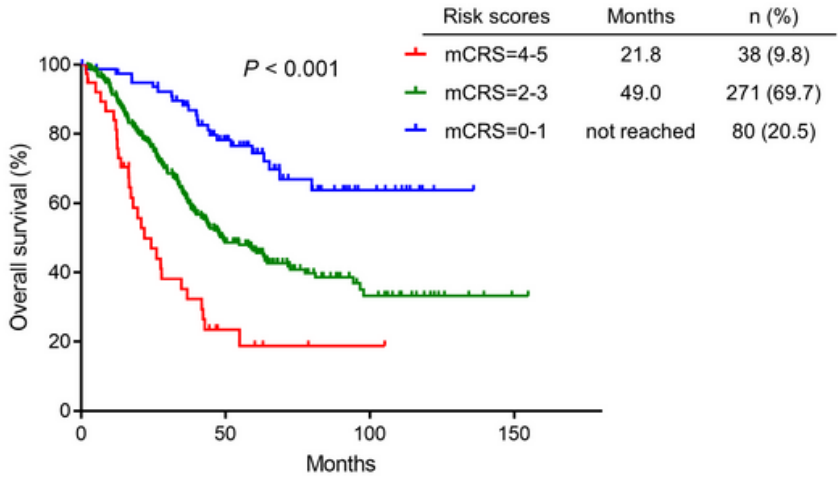

D Validation cohort

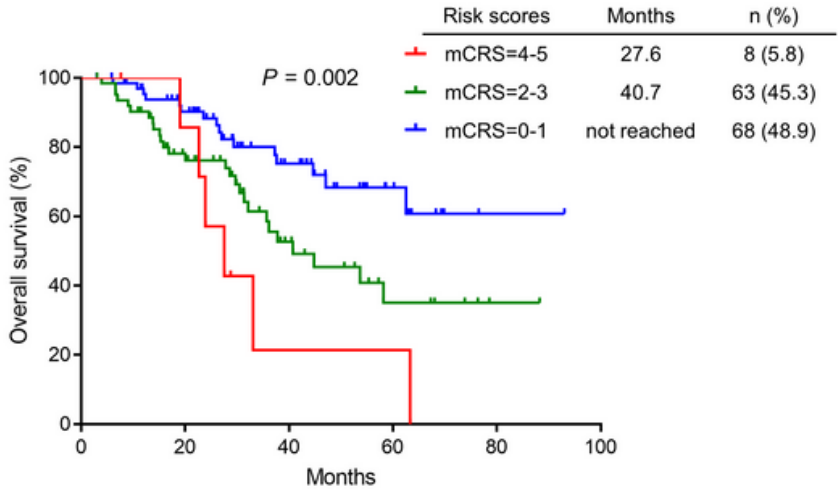

\section{Figure 3}

Survival outcomes stratified by CRS and modified CRS in each cohort. (A-B) Overall survival stratified by different risk groups as defined by CRS and mCRS in the training cohort. (C-D) Overall survival stratified by different risk groups as defined by CRS and mCRS in the validation cohort. Abbreviations: CRS, Clinical Risk Score; mCRS, modified Clinical Risk Score. 

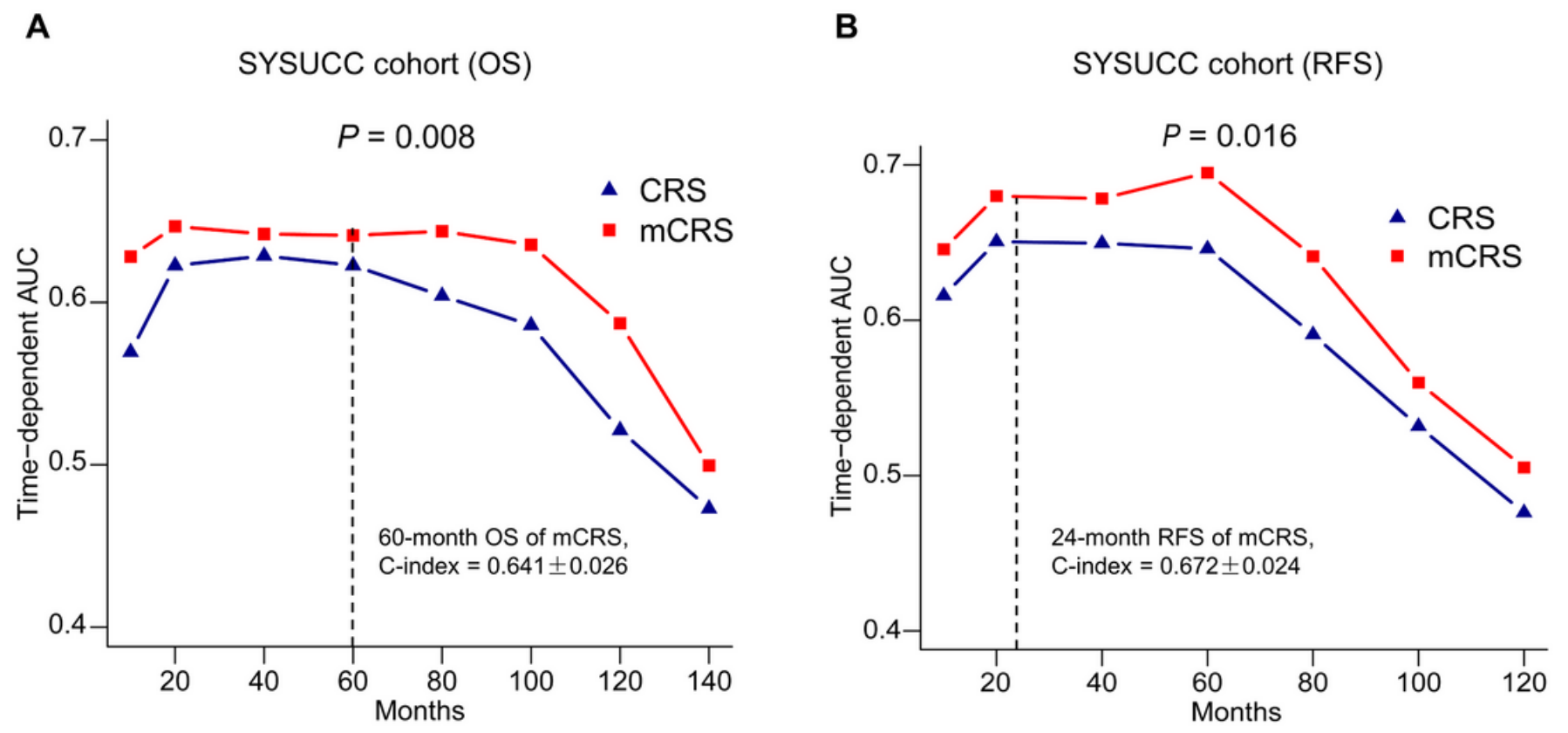

\section{Figure 4}

Receiver operating characteristic (ROC) analysis for the comparison of CRS and mCRS in prediction of survival outcomes in the SYSUCC cohort. (A) AUCs of CRS and mCRS in prediction of overall survival. (B) AUCs of CRS and mCRS in prediction of relapse-free survival. Abbreviations: CRS, Clinical Risk Score; mCRS, modified Clinical Risk Score; AUC, area under curve; C-index, concordance index. 
A

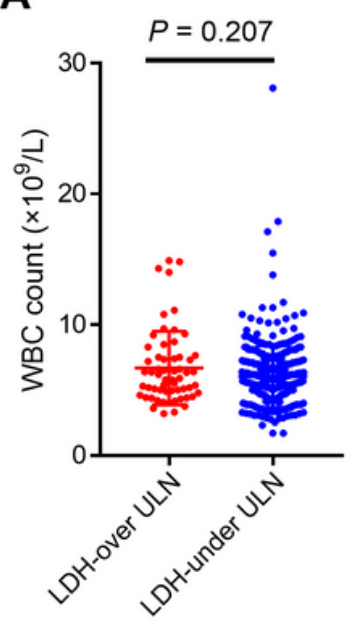

E

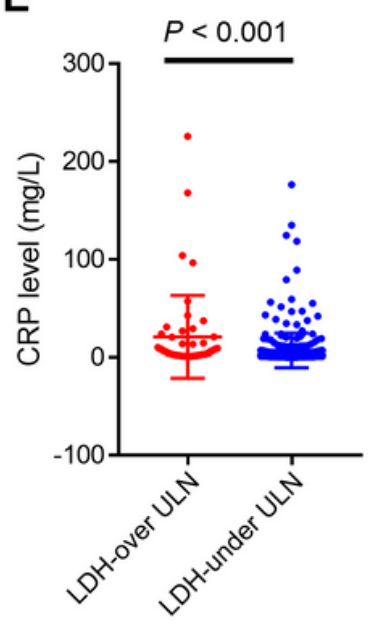

B

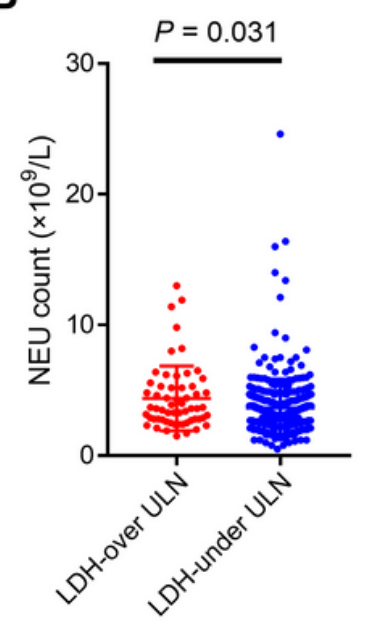

$\mathbf{F}$

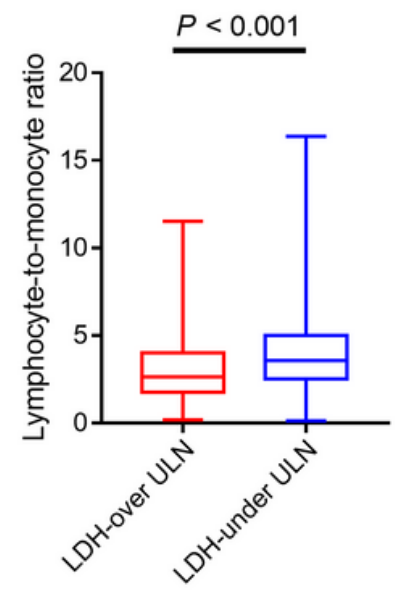

C

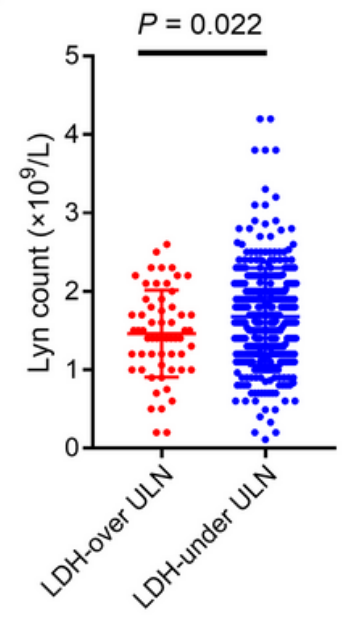

G

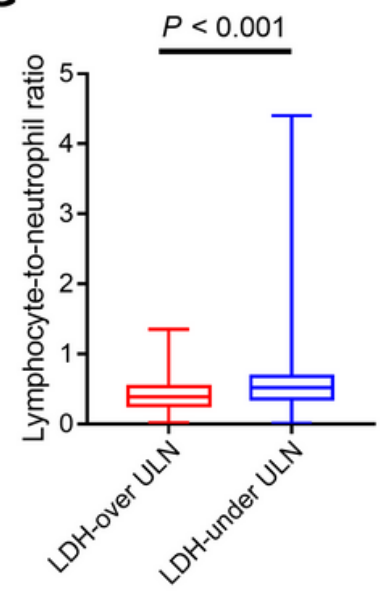

D

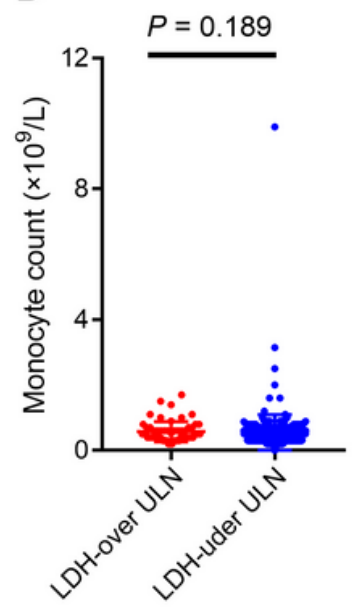

H

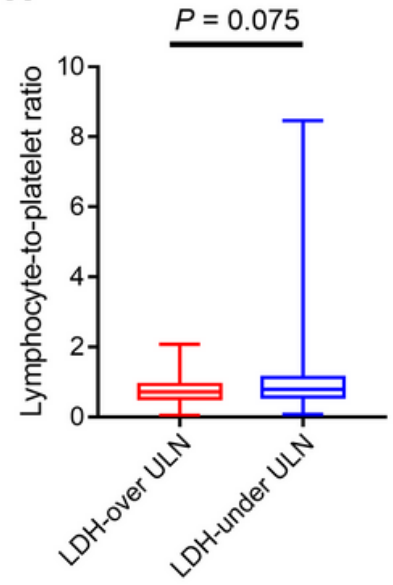

\section{Figure 5}

Associations between preoperative LDH levels and serum immune/inflammation-related factors in the SYSUCC cohort. (A) LDH levels and WBC count. (B) LDH levels and neutrophil count. (C) LDH levels and lymphocyte count. (D) LDH levels and monocyte count. (E) LDH levels and C-reactive protein levels. (F) LDH levels and lymphocyte-to-monocyte ratio. (G) LDH levels and lymphocyte-to-neutrophil ratio. (H) LDH levels and lymphocyte-to-platelet ratio. Abbreviations: WBC, white blood cell; NEU, neutrophil; Lyn, lymphocyte; CRP, C-reactive protein.

\section{Supplementary Files}


This is a list of supplementary files associated with this preprint. Click to download.

- SupplementaryFigure1.tif

- SupplementaryFigure2.tif

- SupplementaryFigure3.tif

- SupplementaryFigure4.tif

- SupplementaryFigure5.tif

- SupplementaryFigure6.tif

- SupplementaryFigure7.tif

- SupplementaryFigurelegends.docx

- SupplementaryTable1.docx

- SupplementaryTable2.docx

- SupplementaryTable3.docx

- SupplementaryTable5.docx

- supplementaryTable4.docx 